\title{
Leadership in health professions education
}

\author{
Vivek Saoji \\ Vice-Chancellor, KLE Deemed to be University, Belagavi, Karnataka, India \\ *Corresponding Author: Vivek Saoji \\ Email: drviveksaoji@yahoo.co.in
}

Leadership is a very fascinating word. There is a lot of excitement around leadership. People are captivated by the idea of leadership. Different people have different notions about leadership. When we talk about leadership or leaders, different attributes \& characteristics comes to our mind of the various prominent leaders. There is however always a cry about good leadership, at the same time we want to become good leaders or work under good leaders. Organisations are also always looking for effective leadership. Many people believe that leadership is a way to improve how they present themselves to others. Academic Institutions, worldwide are engaged on how they will be able to produce effective leaders. There is abundance of literature on leadership and there is no dearth of popular books on leadership. Renowned universities worldwide offer leadership courses and programs of varied durations to the variety of audiences ranging from novices to the Presidents and CEO's of big corporates.

We in health professions education, either in academia or in clinical practice have never been formally introduced to or taught about leadership. We have always had our focus on patient care or the services that we provide and on teaching $\&$ training in our academic institutions. Leadership has never been part of our curriculum, neither was it taught nor assessed. However as health professions educators and health care providers we have a tremendous influence on our students, our patients and their families. In an active career span of approximately 30 years we directly or indirectly influence hundreds and thousands of individuals, therefore it is more the reason that we understand and practice the finer nuances of leadership, so that we can be more effective professionals and bring about the desired change in better way and shorter time to improve the systems.

Further, at present, health professions education as well as health care is passing through a turbulant phase. The world has become borderless, there is a free flow of information, there have been unprecedented advances in science and technology \& particularly in medicine, unfathomable new knowledge is generated every day, there is an onslaught of technology, we are log jammed in an information maze moreover the health care scenario is also rapidly changing, there are issues of patient autonomy and patient safety, the patients are better informed and demanding and have changing needs, this has severely affected the pious doctor patient relationship and among other things led to the spiralling health care costs, to navigate successfully through this dynamic rapidly changing scenario, one of the competency that today's health care professionals need is leadership.
As a matter of fact the landmark article published in the 'Lancet' in 2010, the centenary year of Flexner's report namely "Health Professionals for a New Century .........." puts a lot of emphasis on incorporating leadership and change management as essential competencies in health professions education. In its introductory paragraph the article describes the current scenario as, and I quote "glaring gaps and inequalities in health persists within and between countries, our failure to share the dramatic health advances equitably, coupled with newer health challenges \& our inability to keep pace with these challenges, fragmented, outdated and static curricula that produce ill equipped graduates, mismatch of competencies to patient and population needs, poor teamwork, narrow technical focus, predominant hospital orientation at the expense of primary care and weak leadership" among others.

So if this has to change, we not only need strong leadership but also produce future leaders and change agents. For this to happen we need to introduce leadership as a competency in our curriculum. The Medical Council of India has been trying to address this issue and hopefully the new Competency Based Curriculum incorporating this will be rolled out soon.

We, therefore, need to understand the theory and practice of leadership. Leadership however is a complex process and has multiple dimensions. There have been as many definitions of leadership as many individuals who tried to describe it. It has also been described as per the style, trait, skill or expertise, personality, power relationship, etc. Despite the multiple ways in which leadership has been described, Peter G. Northouse, a renowned a leadership guru and author identified the following components to describe it that a) Leadership is a process b) Leadership involves influence c) Leadership occurs in a group context d) Leadership involves the goal attainment. He therefore defines it as "Leadership is a process whereby an individual influences a group of individuals to achieve a common goal"

This is very true in our context as health care professionals, as I mentioned earlier that we influence or have a chance to influence a large number of people in our professional career and our goal is to improve the health of society as well as to care for the sick and needy, so by this definition, we are all in a leadership position.

The other context that why we need to understand leadership is, today to deliver health care effectively we need to work in teams, be it in highly intense environment of Critical Care, Emergency Room \& Operation Theatres or in a remote Community Health Centre, we have to work in 
teams, coordinate \& communicate effectively with other members of team, assume different roles depending on the situation. Sometime we have to be a member of team \& work in coordination with others members and a leader or sometimes we have to assume the leadership roles and involve everyone and get the work done. As a leader, we have to look at the needs of members, encourage them, support them, provide resources \& feedback to them, so depending on the need we have to change our roles and adapt to the situation quickly, in addition to this the teams could be heterogeneous with members from different professions, different background and different capabilities. The success depends on effective leadership particularly when there is no choice of error and failure.

Since in our profession we have to work in teams and we also have influence over large number of people it is essential to develop leadership as a competency. It should be incorporated in the curriculum so as to improve the overall health care scenario, address the challenges mentioned earlier and bring about the much desired change. This has to be done at undergraduate level, post graduate level and also for the practicing professionals as continuous professional development program. A number of strategies could be adopted to incorporate the leadership competency along with other essential competencies (which at present are also not the part of curriculum but are equally important) like Professionalism, Communication Skills, Ethics, Medical Humanities, Collaboration and Team work, ICT literacy, Creativity, Entrepreneurship, Critical Thinking, etc. which can broadly be described as $21^{\text {st }}$ century skills.

While incorporating these competencies attention has to be paid to include both the theory and practice components so that the learner has an understanding of various theoretical frameworks to effectively practice these skill sets.

At UG and PG level these may be incorporated as regular or continuous programs and not merely as a one day workshop or a refresher courses and for the practicing professionals it can be in the form of CME's where they can get the credit points.

The teaching learning strategies for $\mathrm{UG}$ and $\mathrm{PG}$ education could be in the form of preparation of various modules on each of these competencies. The modules can have the necessary short theoretical underpinning, along with various case scenarios, challenging problems, the case scenarios can be paper based or in the form of videos, group discussions can be conducted on these case scenarios. The learners can be asked to compile a portfolio of activities or reflective logs, they can be in the form of blogs, pictorial essays or in any other creative form. Specific time could be allocated to each of these modules. All these activities can be conducted during the tutorial time, approximately $20-25 \%$ of present tutorial times can be given to these activities particularly in UG education (at present the tutorials are like mini lectures with discussion on triggers like X-Rays, Pathology Specimen, Drugs, ECG's, Instruments, Tubes \& Catheters, Procedures etc. and not necessary as interactive Q/A sessions), $75 \%$ of time still can be retained for these traditional sessions. However dedicating 20 to $25 \%$ time for learning and acquiring these new skills will go a long way in strengthening our curriculum.

For PG's it can be hands on learning during the clinical hours and as a part of their weekly PG training (activity). So it is not difficult to plan and incorporate leadership and other competencies in the curriculum.

Similarly what is taught must be assessed, some newer assessment methods like continuous formative assessment, WBA, 360 evaluation, patient and stakeholder feedbacks etc. can be incorporated. Also the assessment of the logs, portfolio, and reflective summaries can be tried. The learners could be graded as competent, proficient, etc. and certified upon satisfactory completion of these modules. They also could be made mandatory requirements to appear for final or the respective summative examinations.

With incorporating and assessing the leadership competency we will fill the long pending gap in the curriculum and as quoted in the Lancet article progress towards HPE for $21^{\text {st }}$ century moving from present "Informative to Formative and Transformative curriculum".

Leadership therefore is an important competency. It has to be incorporated into our curriculum. Since it is contextual there cannot be any fixed curriculum or teaching learning strategies for that, it has to depend on the specific needs of regions as well as those of learners. There are ample ways in which it can be done, in the write up above we have discussed some of them. The regulatory bodies (MCI, DCI, Nursing Council etc) may bring it as a part of the curriculum, which in any case will be a much needed initiative, but we as faculty have to change our mindset, accept these as necessary components of curriculum and adopt different, innovative strategies to implement it. I am sure this will go a long way in strengthening our curriculum and improving the health care scenario in the country as well as globally.

How to cite: Saoji V. Leadership in health professions education. J Educ Technol Health Sci. 2020;7(1):39-40. 